\title{
Participação das metaloproteinases da matriz na etiopatogenia dos cistos odontogênicos
}

\author{
Role of matrix metalloproteinases in the etiopathogeny of odontogenic cysts
}

Éricka Janine Dantas da Silveira'; Marta Rabello Piva²; Hébel Cavalcanti Galvão ${ }^{3}$; Lélia Batista de Souza³ ${ }^{3}$ Roseana de Almeida Freitas ${ }^{3}$

\section{unitermos}

Cistos odontogênicos

Metaloproteinases

Imuno-histoquímica

\section{resumo}

Visando contribuir para um melhor entendimento do crescimento das lesões odontogênicas e do papel das metaloproteinases da matriz (MMPs) nesse processo, realizou-se uma análise da expressão imunohistoquímica das MMPs -1, -2 e -9, em 15 cistos radiculares (CR), 10 cistos radiculares residuais (CRR), 10 cistos dentígeros (CD) e 10 ceratocistos odontogênicos (CO). Analisou-se, no epitélio e no mesênquima, a imunopositividade das lesões, atribuindo-se os escores: (-) ausência de marcação, (+) marcação focal e (++) marcação difusa. De uma maneira geral verificou-se, no limitante epitelial das lesões, expressão predominantemente difusa da MMP-1 (CRR: 100\%, CD: 70\%) e focal para 53\% dos CRs e $60 \%$ dos COs. Ela variou de focal (CR: 60\% e CO: 100\%) a difusa (CRR: 60\% e CD: 50\%) para a MMP-2 e marcadamente focal para a MMP-9 (100\% dos CR, CRR e CO e 60\% dos CD). No mesênquima, detectou-se expressão destacadamente maior nos COs: $100 \%$ difusa para a MMP-1, enquanto a grande maioria de todos os cistos foi focal; a MMP-2 expressou-se com escore focal em $100 \%$ dos casos, contrastando-se a forte ausência de marcação nos outros cistos; para a MMP-9, 50\% foram difusas e 50\% focais, enquanto a maioria dos outros cistos não exibiu marcação. Os resultados deste estudo sugerem que o crescimento dos cistos odontogênicos pode ser influenciado pela secreção das MMPs. A expressão mais exuberante das MMPs no mesênquima dos COs confirma sua participação ativa no crescimento da lesão, o que pode justificar em parte sua maior agressividade em relação às outras lesões císticas.

\section{abstract}

In an attempt to contribute to a better understanding about the growth of odontogenic lesions and the role of matrix metalloproteinases (MMPs) in this event, the immunoexpression of MMP-1, -2 and -9 was evaluated in 15 radicular cysts (RCs), 10 residual radicular cysts (RRCs), 10 dentigerous cysts (DCs) and 10 odontogenic keratocysts (OKs). To the analysis of epithelium and supporting mesenchyme, the following scores were utilized: negative (-), focal (+) and diffuse (++). Our results showed that the epithelial lining of the RRCs (100\%) and DCs (70\%) was diffuse to MMP-1, while to the RCs (53\%) and OKs (60\%) was predominantly focal. MMP-2 immunoscores ranged from focal in the lining of OKs (100\%) and RCs (60\%) to diffuse in RRCs (60\%) and DCs (60\%). With relation to MMP-9, the lining of all lesions was immunoexpressed focally (100\% of RCs, RRCs and OKs and $60 \%$ of DCs). In relation to mesenchyme, the immunoexpression was higher in all OKs: the MMP-1 scores were diffuse (100\%), while most of the other studied lesions were focal; all OKs focally immunoexpressed the MMP-2, what differed from the other cysts which did not express this MMP. To MMP-9, the mesenchyme of the OKs were immunoscored as focal (50\%) and diffuse (50\%), while most of other cysts had not shown staining. These results suggest that the growth of the odontogenic cysts may be influenced by the secreted MMPs. The most exuberant expression of the MMPs in mesenchyme of the OKs confirms its active participation in the growth, what may in part justify its bigger aggressiveness in comparison to other cystic lesions.

\section{key words}

Odontogenic cysts

Metalloproteinases

Immunohistochemistry

\footnotetext{
1. Doutoranda do Programa de Pós-Graduação em Patologia Oral, Departamento de Odontologia da Universidade Federal do Rio Grande do Norte (UFRN).

2. Doutoranda do Programa de Pós-Craduação em Patologia Oral, Departamento de Odontologia da UFRN; professora do Departamento de Odontologia da Universidade Federal de Sergipe, (UFS).

3. Professora-doutora do Programa de Pós-Graduação em Patologia Oral, Departamento de Odontologia da UFRN.

Trabalho realizado no laboratório de imuno-histoquímica do Programa de Pós-Graduação em Patologia Oral do Departamento de Odontologia da UFRN.
} 


\section{Introdução}

Os cistos odontogênicos são as lesões osteodestrutivas mais comuns no esqueleto humano, com histogênese comum a partir de remanescentes epiteliais do órgão do esmalte, mas com comportamentos clínicos diferentes. Alguns cistos odontogênicos, como o cisto radicular (CR) e o cisto dentígero (CD), exibem curso clínico indolente com crescimento lento e assintomático ${ }^{(15)}$, porém o ceratocisto odontogênico (CO), descrito na última classificação de cistos e tumores odontogênicos da Organização Mundial da Saú$\mathrm{de}^{(3)}$ como tumor odontogênico benigno, agora denominado tumor odontogênico ceratocístico, apresenta comportamento clínico agressivo e elevado índice de recidiva.

O mecanismo de crescimento dessas lesões ainda é controverso. Alguns autores relatam que sua expansão e seu crescimento envolvem a invasão e a destruição da matriz extracelular (MEC) osteóide e da membrana basal, que é influenciada tanto pela proliferação do epitélio cístico como pela velocidade de destruição do tecido ósseo subjacente.

Estudos recentes, tanto na remodelação tecidual como durante o desenvolvimento de processos patológicos, têm demonstrado que as metaloproteinases da matriz (MMPs) parecem exercer influências importantes ${ }^{(4,12)}$. As MMPs constituem uma família de aproximadamente 24 enzimas classificadas em cinco grupos principais: colagenases (MMP-1, -8 e-13); gelatinases (MMP-2 e -9), também conhecidas como colagenases do tipo IV; estromelisinas (MMP-3, -10 e-11, tipo membrana (MT-MMPs), além de outras ${ }^{(6,12,18)}$. Visando conhecer melhor e esclarecer o papel das MMPs nos mecanismos de expansão cística, este trabalho tem como objetivo estudar e comparar a expressão imuno-histoquímica das MMPs -1, -2 e -9, em CR, cisto radicular residual (CRR), CD e CO.

\section{Material e métodos}

A amostra selecionada do Serviço de Patologia Oral do Departamento de Odontologia da Universidade do Rio Grande do Norte (UFRN) consta de 45 casos (10 CRRs, 15 CRs, 10 CD e 10 COs) que foram diagnosticados com base em dados clínicos, radiográficos e histopatológicos corados através da técnica de hematoxilina e eosina.

Todo o material selecionado encontrava-se fixado em formol a $10 \%$ e emblocado em parafina, sendo feitos cortes histológicos de $3 \mu \mathrm{m}$ de espessura colocados sobre lâminas de vidro contendo adesivo à base de 3-aminopropiltrietoxi-silano (Sigma Chemical CO., St. Louis, MO, USA). Os cortes histológicos foram desparafinados em xilol, reidratados em seqüência de álcool até a água e lavados em duas águas destiladas por cinco minutos cada. Foi feito o bloqueio da peroxidase endógena com peróxido de hidrogênio 20 volumes, lavadas em água e incubadas em tris(hidroximetil)aminometano (TRIS-HCL), $\mathrm{pH} \mathrm{7,4}$ por 10 minutos. Os cortes foram encubados com anticorpo monoclonal anticamundongo, diluído em solução tampão de TRIS-HCL (Tabela 1), para incubação com o complexo estreptoavidina-biotina, em diluição de 1:100 por 30 minutos. Para revelação foi utilizada a solução cromógena de diaminobenzidina a 0,03\%, diluída em TRIS-HCL adicionada de $0,6 \mathrm{ml}$ de peróxido de hidrogênio 20 volumes em câmara escura por três minutos e, como contracoloração, a hematoxilina de Mayer por 10 minutos, lavando em água após cada passo. Finalizando o processo, fez-se a desidratação em álcool e a diafanização em xilol para montagem da lamínula com Permount.

A imunomarcação foi verificada por dois examinadores em momentos distintos em um estudo duplo-cego, em que foi inicialmente analisada a ausência ou a presença de marcação, atribuindo-se os escores: - (ausência de marcação), + (marcação focal, menos de 10\% de células marcadas) e ++ (marcação difusa - mais de 10\% das células marcadas) ${ }^{(12)}$. A expressão das MMPs foi analisada de forma separada tanto no epitélio como na cápsula cística, onde tal marcação foi verificada em fibroblastos, células endoteliais e células inflamatórias. Após obtenção dos dados da imunomarcação foi realizada análise descritiva dos resultados.

Tabela 1 Especificações dos anticorpos utilizados

\begin{tabular}{lcccc}
\hline Anticorpo & Clone & Diluição & Recuperação antigênica & Tempo \\
Anti-MMP-1* & 41-1E5 & $1: 100$ & Citrato, pH 6, 30', Steamer & Overnight \\
Anti-MMP-2** & 17B11 & $1: 60$ & EDTA, pH8, 30', Steamer & $60^{\prime}$ \\
Anti-MMP-9** & 1 A5 & $1: 60$ & Citrato, pH6, 30', Steamer & Overnight \\
\hline
\end{tabular}

${ }^{*}$ Calbiochem; ${ }^{* *}$ Novocastra Laboratories. 


\section{Resultados}

\section{Resultados morfológicos}

Os 15 casos de CRs exibiram cavidade patológica revestida ou parcialmente revestida por epitélio pavimentoso estratificado não-ceratinizado, de espessura variável, às vezes com projeções arciformes e acantose nas áreas onde o infiltrado inflamatório era mais intenso. A cápsula cística era constituída por tecido conjuntivo fibroso de densidade variada, contendo intenso infiltrado inflamatório predominantemente linfoplasmocitário em 11 casos e infiltrado de intensidade moderada em quatro casos, podendo ser evidenciados, em alguns, corpúsculos de Russel e neutrófilos.

O revestimento dos CRRs era semelhante ao dos CRs, $O$ infiltrado inflamatório presente na cápsula foi intenso em quatro casos e variou de moderado a fraco em seis casos.

Os CDs exibiram epitélio pavimentoso estratificado não-ceratinizado delgado, contínuo, em sua maior extensão, e cápsula constituída por tecido conjuntivo fibroso de densidade variada com infiltrado inflamatório variando de escasso a moderado em sete dos 10 casos. Em três casos observou-se intensa inflamação com predominância de linfócitos e plasmócitos.

Os COs exibiram epitélio pavimentoso estratificado paraceratinizado com seis a oito camadas celulares, células basais de núcleos hipercromáticos em paliçada e polarizados e camada superficial corrugada, havendo em certas áreas o desprendimento desse epitélio da cápsula. O tecido conjuntivo subjacente mostrou-se com feixes delicados de fibras colágenas, sede de infiltrado inflamatório de densidade variada em todos os casos.

\section{Resultados imuno-histoquímicos}

A imunomarcação para as MMPs -1, -2 e -9 mostrouse de forma variada tanto no epitélio como no tecido conjuntivo dos CR, CRR, CD e CO estudados, podendo ser evidenciada na Tabela 2 e nas Figuras 1, 2, 3, 4 e 5.

Em geral, verificou-se, no limitante epitelial das lesões, expressão predominantemente difusa com mais de $10 \%$ das células positivas (++) para MMP-1 (CRR: 100\%, CD: 70\%), enquanto em $53 \%$ dos CRs e $60 \%$ dos COs a mesma foi focal (+). Tal imunomarcação variou de focal (CR: 60\% e CO: 100\%) a difusa (CRR: $60 \%$ e CD: $50 \%$ ) para a MMP-2 e marcadamente focal com menos de $10 \%$ das células marcadas (+) para a MMP-9 ( $100 \%$ dos CR, CRR e CO e $60 \%$ dos CD). No mesênquima, detectou-se expressão destacadamente maior nos COs: $100 \%(++)$ para a MMP-1, enquanto a grande maioria de todos os cistos foi (+); a MMP-2 expressou-se com escore (+) em $100 \%$ dos casos, contrastando com forte ausência de marcação nos cistos; e para a MMP-9, 50\% foram (++) e $50 \%(+)$, comparando-se também a um grande número de casos negativos nas outras entidades.

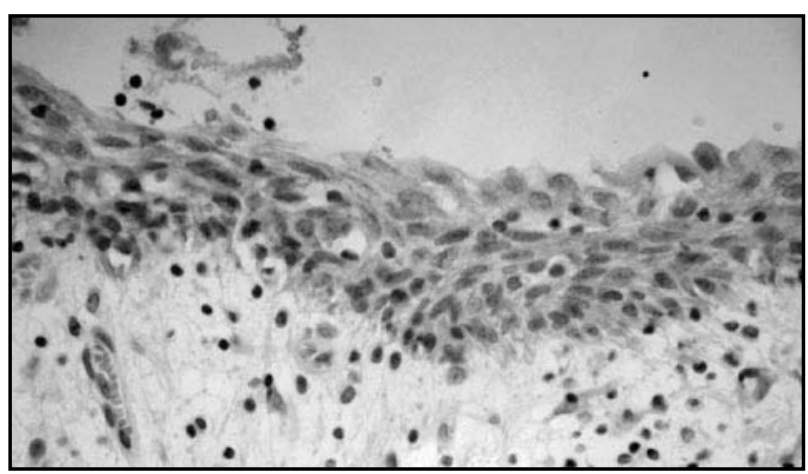

Figura 1 - Marcação difusa da MMP-1 no revestimento epitelial e focal na cápsula de cisto radicular residual (SABC, 200x)

\section{Tabela 2}

Expressão imuno-histoquímica das metaloproteinases em cistos radiculares, cistos radiculares

\begin{tabular}{|c|c|c|c|c|}
\hline & CR & CRR & CD & $\mathrm{CO}$ \\
\hline \multicolumn{5}{|l|}{ MMP-1 } \\
\hline Epitélio & $7(++) 8(+)$ & $10(++)$ & $7(++) 3(+)$ & $6(+) 4(-)$ \\
\hline Mesênquima & $3(++) 12(+)$ & $10(+)$ & $10(+)$ & $10(++)$ \\
\hline \multicolumn{5}{|l|}{ MMP-2 } \\
\hline Epitélio & $9(+) 6(-)$ & $6(++) 4(+)$ & $5(++) 5(+)$ & $10(+)$ \\
\hline Mesênquima & $4(+) 11(-)$ & $7(-) 3(+)$ & $6(+) 4(-)$ & $10(+)$ \\
\hline \multicolumn{5}{|l|}{ MMP-9 } \\
\hline Epitélio & $15(+)$ & $10(+)$ & $4(++) 6(+)$ & $10(+)$ \\
\hline Mesênquima & $10(-) 5(+)$ & $10(-)$ & $7(+) 3(-)$ & $5(++) 5(+)$ \\
\hline
\end{tabular}




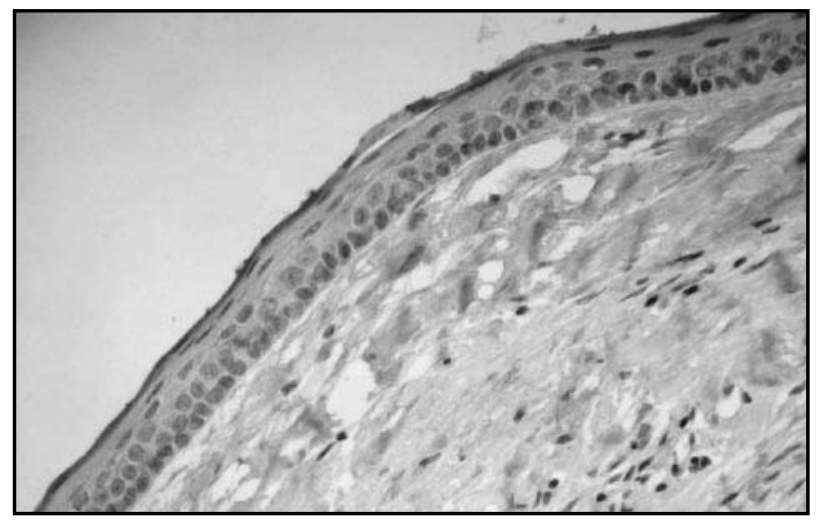

Figura 2 - Imunopositividade da MMP-1 em células epiteliais e mesenquimais em ceratocisto odontogênico (SABC, 200x)

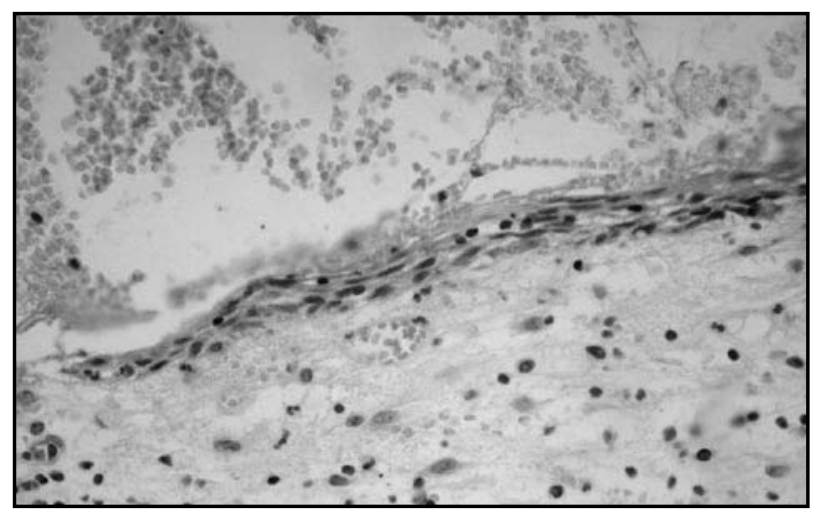

Figura 3 - Imunopositividade difusa no componente epitelial e focal no mesênquima para MMP-2 em cisto dentígero (SABC, 200x)

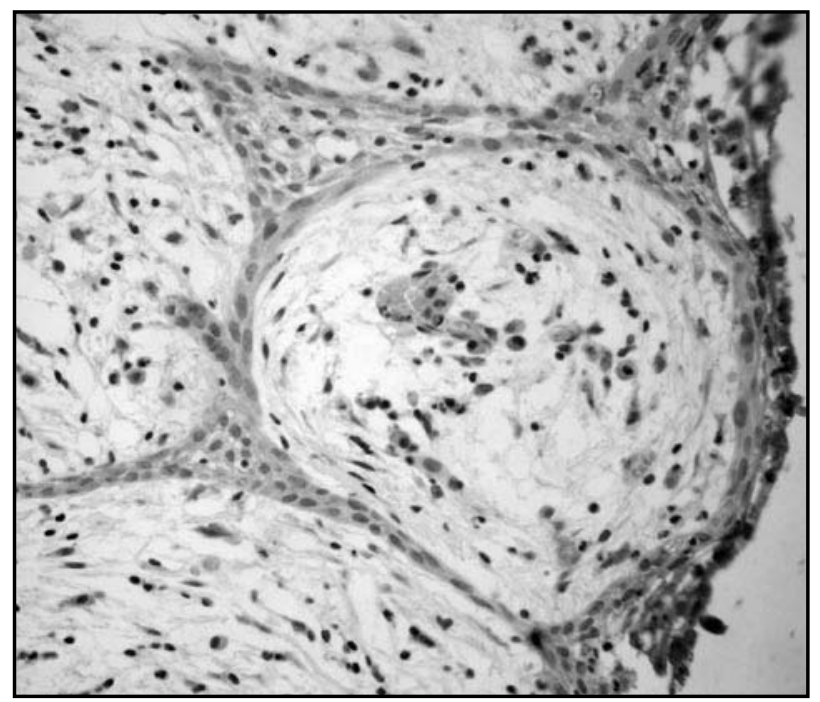

Figura 4 - Imunomarcação para MMP-9 no epitélio e na cápsula de cisto radicular (SABC, 200x)

\section{Discussão}

De acordo com Teronen et al.(19), a expansão dos cistos odontogênicos dos ossos maxilares pode envolver a degradação tanto da matriz osteóide como da membrana

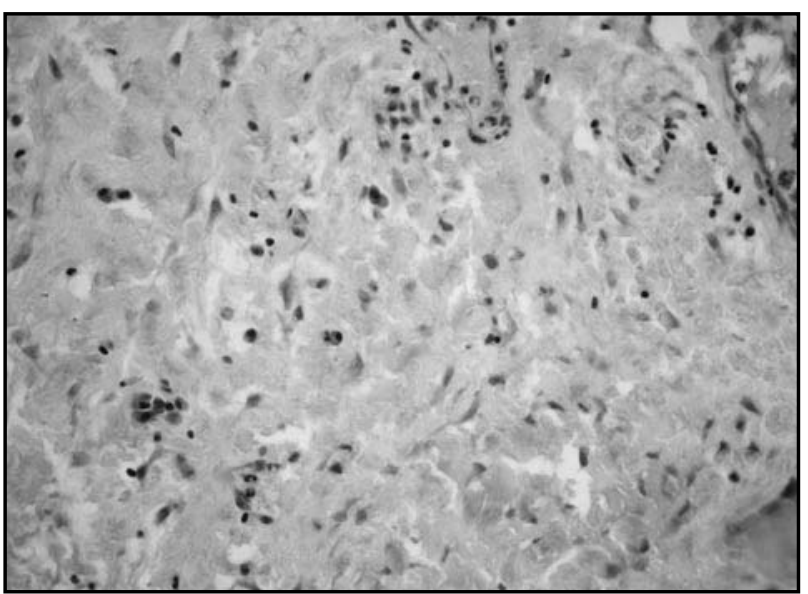

Figura 5 - Positividade difusa para MMP-9 em células mesenquimais em ceratocisto odontogênico (SABC, 200x)

basal. Algumas pesquisas presentes na literatura ressaltam igualmente a participação das proteínas da matriz extracelular (MEC) e a da atividade proliferativa do epitélio no seu mecanismo de expansão, citando o estudo de Oliveira et al. ${ }^{(16)}$, que apontaram diferenças na constituição das membranas basais dos CRs, CDs e COS e verificaram fraca expressão das proteínas dessa estrutura nos COs, inferindo que interações entre epitélio e cápsula poderiam contribuir, em parte, para o padrão de crescimento mais agressivo dessa entidade ${ }^{(16)}$.

Os cistos odontogênicos dos maxilares podem ser classificados, com base na sua etiologia, em inflamatórios e de desenvolvimento. O CR é de origem inflamatória, com patogênese iniciada a partir da necrose da polpa, conduzindo a inflamação até o periápice, o que resulta em proliferação dos restos epiteliais de Malassez, formação da cavidade e expansão cística ${ }^{(13)}$.

O CRR constitui um tipo de CR presente num sítio de exodontia prévia com etiopatogenia igual à desta entidade, mas estando o dente fonte da inflamação ausente ${ }^{(15)}$.

O surgimento do $C D$ e do $C O$ não está associado a estímulo inflamatório. $\mathrm{O} C D$, classificado como cisto de desenvolvimento, se origina pela separação do folículo da coroa de um dente incluso ${ }^{(15)}$.

Barnes et al.(3), na última classificação de cistos e tumores odontogênicos da OMS, classificaram o CO como tumor benigno, de natureza odontogênica, com origem provável a partir da lâmina dentária pós-funcional ou de remanescentes e extensões de células basais do epitélio de revestimento, já que tal entidade exibe potencial agressivo, comportamento infiltrativo com tendência à multiplicidade quando associado à síndrome do carcinoma nevóide basocelular (síndrome 
de Gorlin). Segundo esses autores, a etiopatogenia do CO encontra-se relacionada com a perda alélica de um ou mais loci no gene PTCH, o que conduz a uma superexpressão das proteínas bcl-2 e TP53, sustentando a hipótese de que 0 cisto representa um neoplasma ${ }^{(3)}$.

Em decorrência das incertezas e discordâncias em relação aos mecanismos envolvidos no crescimento e na expansão desses cistos, nesta pesquisa foi analisada, através da imuno-histoquímica, a expressão da MMP-1 (colagenase) e das MMPs-2 e -9 (gelatinases) em CR, CRR, CD e CO. O trabalho também foi impulsionado pela escassez de pesquisas utilizando essas proteínas nessas entidades e pelas citações de Teronen et al.(19), que verificaram que células em cultura de cistos radiculares, cistos dentígeros e ceratocistos odontogênicos são produtoras de colagenases intersticiais, como MMP-1, e mediadores pró-inflamatórios, como prostaglandinas, citocinas e fatores de crescimento. Os últimos são sintetizados por fibroblastos, células epiteliais, macrófagos e células ósseas.

Vale ressaltar que o método utilizado por nós não torna possível verificar a atividade enzimática das MMPs ou distinguir suas formas latentes ou ativas, conforme citado por de Vicente et al. ${ }^{(6)}$ que também utilizaram essa mesma técnica. Porém, lkebe et al.(11) demonstraram que a zimografia utilizada para verificar a atividade das MMPs esteve correlacionada significativamente com o grau de marcação imuno-histoquímica.

Ainda segundo de Vicente et al.(6), a completa reabsorção da matriz óssea também envolve a ação de outras MMPs, como as gelatinases (MMP-2, -8 e -9 ), as quais atuam na degradação de outros componentes da matriz como colágenos IV, V, VII e X, laminina, elastina e fibronectina. Nossos resultados mostraram que todas as lesões estudadas produzem as MMPs -1, - 2 e - 9 de forma variada.

As MMPs constituem uma família de endopeptidases, caracterizadas por sua capacidade de degradar a MEC na dependência de $\mathrm{Zn++}$. Elas atuam em proliferação e diferenciação celular, remodelação da matriz, vascularização e migração celular. No presente estudo foi analisada a expressão das MMPs - 1 , -2 e -9 tanto nas células epiteliais como na cápsula dos $C R, C R R, C D$ e $C O$, sendo verificado que tais células são capazes de secretar essas proteínas, as quais podem atuar na degradação da matriz óssea, contribuindo para o crescimento cístico. A afirmativa é baseada nos relatos de Delaissé et al. ${ }^{(7)}$ e Chirguren e Gui$\mathrm{se}^{(5)}$, os quais reportaram ser a matriz óssea rica em fatores de crescimento e citocinas, onde as MMPs não somente solubilizam tal estrutura, como também regulam o início da reabsorção. Também tem base nas afirmativas de Okada et al. ${ }^{(17)}$ de que as MMPs -2 e -9 são essenciais na completa degradação do colágeno, atividade associada à clivagem inicial realizada pela MMP-1.

Delaissé et al.(7) e Holliday et al. ${ }^{(10)}$ sugeriram que a MMP-1, ou colagenase-1, pode atuar de forma direta ou indireta na iniciação do processo de reabsorção óssea, por estimular a liberação de fatores ativadores de osteoclastos presentes na matriz intersticial e a eliminação de osteóide não-mineralizado na superfície óssea, permitindo o acesso de osteoclastos à fração mineralizada subjacente, além de poder promover a geração de fragmentos de colágeno degradado, os quais por sua vez ativariam os osteoclastos. Em nossa amostra, essa MMP foi a que esteve presente de forma mais marcante nos espécimes estudados, ressaltando sua presença expressiva nos epitélios de CRs, CRRs, CDs e tecido conjuntivo dos COs. Sua presença tanto no epitélio como nas cápsulas dessas entidades se explica pelo fato de que a mesma pode ser produzida por células epiteliais, fibroblastos, macrófagos, plasmócitos, linfócitos e neutrófilos $^{(9)}$. Concordando com a referida pesquisa, as amostras por nós analisadas exibiram marcação em células epiteliais, fibroblastos e células do infiltrado inflamatório presentes em cápsula e mesênquima dessas lesões.

Um número cada vez maior de pesquisas reforça que tanto o epitélio como a cápsula podem exercer influências nos mecanismos de crescimento e expansão cística. Esse fato talvez explique a presença marcante da MMP-1 nos epitélios dos CRs, CRRs e CDs, o que pode sugerir que nessas lesões o tecido epitelial constitui importante fonte dessa proteína, contrariamente ao $\mathrm{CO}$, cujas células do mesênquima foram suas principais fontes, havendo pouca produção por parte das células epiteliais, já que houve apenas marcação focal em seis casos e em quatro casos não se evidenciou positividade. Tal fato reforça o papel do mesênquima na indução do crescimento e da expansão do $\mathrm{CO}$, estando parcialmente de acordo com as pesquisas de Kumamoto et al. ${ }^{(12)}$, que detectaram a presença da MMP-1 somente em células mesenquimais dos germes dentais e células do estroma dos ameloblastomas.

Realizando-se análise comparativa em relação à imunoexpressão da MMP-1 entre os dois cistos inflamatórios e o $C D$, percebe-se que a mesma esteve presente em todos os casos analisados e ainda de forma intensa em sete casos no epitélio dos CRs e CDs e em todos os casos de CRRs, verificando, dessa forma, não haver diferenças marcantes em tal imunomarcação entre as três entidades. É possível explicar o fato com base no estudo de Ala-aho e Kahari ${ }^{(1)}$ 
relatando que a MMP-1 pode ser produzida em resposta à presença de citocinas, auxiliando o processo de invasão em neoplasias; então, as células inflamatórias presentes nas cápsulas desses cistos podem estar secretando citocinas que estariam induzindo a expressão dessa proteína nas referidas entidades.

Tanto a MMP-2 como a MMP-9 constituem gelatinases (A e $B$ respectivamente) ${ }^{(14)}$; a diferença principal entre as duas é que apenas a MMP-2 exibe capacidade de degradar colágeno do tipo $\mathrm{I}^{(2)}$. Porém, segundo Fridman et al. ${ }^{(8)}$, a presença de sítios de ligação às gelatinas confere a essas proteínas capacidade de estabelecer ligações de alta afinidade com o colágeno extracelular. Isso favorece sua permanência em associação à MEC, que atuaria como fonte de reserva para todas as MMPs. Foi verificado por de Vicente et al.(6) que as MMPs-2 e - 9 encontram-se envolvidas na angiogênese e no crescimento dos tumores, sugerindo associação dessas gelatinases com o comportamento agressivo e cursos clínicos imprevisíveis em alguns neoplasmas humanos.

Em relação aos achados para marcação das MMPs-2 e -9 no presente estudo, foi verificado que a MMP-2 exibiu marcação predominantemente focal ou ausente, ressaltando apenas marcação difusa em seis dos 10 casos de CRRs e cinco casos de $C D$, além de estar presente de forma focal tanto no componente epitelial como no mesênquima de todos os COs, havendo negatividade na cápsula da maioria dos casos de CR e CRR.

No que se refere à expressão da MMP-9, foi observada marcação mais intensa no mesênquima dos COs. Nos CRs, CRRs e CD, a marcação foi predominantemente focal, com negatividade na cápsula da maioria dos $\mathrm{CR}$ e todos os CRRs.

Kumamoto et al. ${ }^{(12)}$ encontraram reatividade para as MMPs - 2 e - 9 nos componentes mesenquimais em germes dentais, evidenciando apenas fraca positividade para essas proteínas no componente epitelial e corroborando parcialmente os achados do presente estudo, já que os cistos odontogênicos inflamatórios e o CD preservaram de forma fraca a imunoexpressão dessas MMPs em seu epitélio.

Os mesmos autores encontraram também forte positividade para MMP-9 no estroma dos ameloblastomas, sugerindo que o aumento na produção dessa proteína pelas células neoplásicas está relacionado com a transformação dos tecidos odontogênicos e a agressividade da entidade ${ }^{(12)}$. Tal afirmativa justifica a presença mais marcante da MMP-9 no componente mesenquimal dos $\mathrm{CO}$, explicando de certa forma que isso pode contribuir para seu comportamento mais agressivo em relação aos cistos inflamatórios e aos CDs e reforçando ainda mais a hipótese de seu comportamento semelhante ao do ameloblastoma, o que pode, em parte, induzir à teoria da sua classificação como tumor odontogênico benigno.

A produção da IL-1 $\alpha$ esteve relacionada à ativação da MMP-9 e MMP-2 nas pesquisas de Kumamoto et al., em 2000 e 2002, respectivamente citados em 2003, reportando que esse evento encontra-se relacionado com o mecanismo de crescimento dos $\operatorname{COs}^{(12)}$.

Com base nos resultados encontrados na presente pesquisa, pode-se concluir que o mecanismo de expansão tanto dos COs como das outras entidades estudadas pode ser influenciado, e até mesmo conduzido, pela secreção das metaloproteinases da matriz (que podem estar sendo liberadas tanto pelo componente epitelial como por células mesenquimais) e que a expressão mais exuberante das MMPs no mesênquima dos COs pode justificar, em parte, sua maior agressividade em relação às outras lesões císticas.

\section{Referências}

I. ALA-AHO, R.; KAHARI, V.M. Collagenases in cancer. Biochimie, v. 87, n. 3-4, p. 273-86, 2005.

2. BJÖRKLUND, M.; KOIVUNEN, E. Gelatinase-mediated migration and invasion of cancer cells. Biochim Biophys Acta, v. 1755, n. I, p. 37-69, 2005.

3. BARNES, L. et al. World Health Organization classification of tumors - pathology and genetics of head and neck tumors. Lyon: IARC Press, 2005.

4. BAST, B.T. et al. The expression of apoptotic proteins and matrix metalloproteinases in odontogenic myxomas. J Oral Maxillofac Surg, v. 61, n. 12, p. 1463-66, 2003.
5. CHIRGUREN, J.M.; GUISE,T.A. Molecular mechanisms of tumorbone interactions in osteolytic metastases. Crit Rev Eukaryot Gene Expr, v. 10, n. 21, p. 59-78, 2000.

6. DEVICENTE, J.C. et al. Expression and clinical significance of matrix metalloproteinase-2 and matrix metalloproteinase-9 in oral squamous cell carcinoma. Oral Oncol, v. 4I, n. 3, p. 283-93, 2005.

7. DELAISSÉ. J.M.et al. Proteinases in bone resorption: obvious and less obvious roles. Clin Chim Ac, v. I5, n. 2, p. 223-34, 2000.

8. FRIDMAN, R. et al. Cell surface association of matrix metalloproteinase-9 (gelatinase B). Cancer Metastasis Rev, v. 22, n. 2-3, p. 153-66, 2003. 
9. HEIDINGER, M. et al. Modulation of autocrine TNF-alphastimulated matrix metalloproteinase 9 (MMP-9) expression by mitogen-activated protein kinases in THP-I monocytic cells. Biol Chem, v. 387, n. I, p. 69-78, 2006.

10. HOLLIDAY, L.S. et al. Effects of matrix metalloproteinase inhibitors on bone resorption and orthodontic tooth movement. J Dent Res, v. 82, n. 9, p. 687-91, 2003.

I I. IKEBE, T. et al. Gelatinolytic activity of matrix metalloproteinase in tumor tissues correlates with the invasiveness of oral cancer.Clin Exp Metastasis, v. 17, n. 4, p. 315-23, 1999.

12. KUMAMOTO, $\mathrm{H}$. et al. Immunohistochemical detection of matrix metalloproteinases (MMPs) and tissue inhibitors of metalloproteinases (TIMPs) in ameloblastomas.J Oral Pathol Med, v. 32, n. 2, p. I I4-20, 2003.

|3. MEHGJI, S. et al. The role of endotoxin and cytokines in the pathogenesis of odontogenic cysts. Archiv Oral Biol, v. 4I, n. 6, p. 523-31, 1996.
14. MONTELEONE, G. et al. Control of matrix metalloproteinase production in human intestinal fibroblasts by interleukin 21 . Gut, v. 55, n. 12, p. 1774-80, 2006

15. NEVILLE, B.W. et al. Oral and maxillofacial pathology. Philadelphia: Saunders, 2004

16. OLIVEIRA, M.D. et al. Immunohistochemical study of components of the basement membrane in odontogenic cysts. Pesqui Odontol Bras, v. I 6, n. 2, p. I57-62, 2002.

17. OKADA, Y. et al. Localization of matrix metalloproteinase 9 (92-kilodalton gelatinase/type IV collagenase = gelatinase B) in osteoclasts: implications for bone resorption. Lab Invest, v. 72 , n. 3, p. 31।-22, 1995.

18. POLETTE,M. et al. Tumour invasion and matrix metalloproteinases. Crit Rev Oncol Hematol, v. 49, n. 3, p. 179-86, 2004.

19. TERONEN, O. et al. Identification and characterization of gelatinases/type IV collagenases in jaw cysts. J Oral Pathol Med, v. 24, n. 2, p. 78-84, 1995.

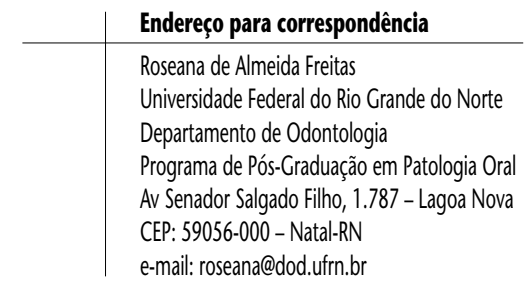

